\title{
Préinventaire des mines anciennes du Jura
}

Prospection thématique (2001)

Denis Morin, Michel Philippe et Patrick Rosenthal

\section{CpenEdition}

1 Journals

Édition électronique

URL : https://journals.openedition.org/adlfi/8521

ISSN : 2114-0502

Éditeur

Ministère de la Culture

Référence électronique

Denis Morin, Michel Philippe et Patrick Rosenthal, « Préinventaire des mines anciennes du Jura »

[notice archéologique], ADLFI. Archéologie de la France - Informations [En ligne], Bourgogne-FrancheComté, mis en ligne le 01 mars 2001, consulté le 28 juillet 2021. URL : http://journals.openedition.org/ adlfi/8521

Ce document a été généré automatiquement le 28 juillet 2021.

(c) ministère de la Culture et de la Communication, CNRS 


\section{Préinventaire des mines anciennes du Jura}

Prospection thématique (2001)

Denis Morin, Michel Philippe et Patrick Rosenthal

\section{NOTE DE L'ÉDITEUR}

Organisme porteur de l'opération : CNRS

1 Le département du Jura comporte de nombreux vestiges miniers anciens liés à l'exploitation de substances minérales comme le fer, le lignite ou le sel.

2 Les mines de sel de Salins furent peut-être les plus importantes d'Europe au Moyen Âge.

3 Un premier inventaire de ce patrimoine a été effectué à partir des dépouillements et des sondages dans les fonds d'archives parisiens.

4 Les dépouillements ont eu pour cadre, d'une part, les visites de mines effectuées par les ingénieurs des mines au XIX ${ }^{\mathrm{e}}$ s., d'autre part, les enquêtes préalables à l'établissement d'usines hydrauliques, de hauts fourneaux et la question de l'origine de leur approvisionnement en minerai. D'autres recherches ont porté plus largement sur des pistes documentaires concernant l'activité minière pendant la seconde guerre mondiale (Archives nationales) et une série d'enquêtes géologiques et minières effectuées en Franche-Comté au XVIII ${ }^{\mathrm{e}} \mathrm{s}$. (Bibliothèque nationale). Cette recherche préalable devra s'enchaîner sur le travail plus systématique d'inventaire des gisements miniers, commune par commune, localisant lieux d'extraction, établissements industriels, période d'extraction, qualité des minerais et production en général.

5 Vingt-neuf communes ont fait l'objet d'une ou de plusieurs fiches. Les informations font l'objet d'une transcription informatique systématique sur fichier Gobannon.

6 Vingt-neuf communes ont fait l'objet d'une ou plusieurs fiches, à travers le seul dépouillement de trois cartons fort riches d'intérêt. Les fiches prennent en compte la localisation (commune, lieu-dit ou gîte), la nature du minerai, la propriété et 
l'exploitant, la forme d'extraction (mine ou minière) et la qualité de celui-ci (aux dires des ingénieurs des mines), la destination (haut fourneau, autre établissement), l'existence de plan, de données sur l'hydrologie et la technique d'exploitation (l'état d'avancement de galeries, de puits, des investissements particuliers), enfin des observations relatives, par exemple, aux problèmes économiques ou commerciaux soulevés par les ingénieurs des mines, des observations et la source datée du document. Les renseignements recueillis sont davantage nourris par les grands domaines concessionnés comme les mines de fer d'Ougney et de Pagney et par les mines de sel de Grozon et de Salins. Ils rendent compte de périodes d'exploration intensive et de moments plus délicats issus de la concurrence d'autres zones de production, ou de la baisse d'activité des établissements de traitement comme les hauts fourneaux.

7 Ces résultats ponctuels serviront à la préparation d'une campagne de prospection et le dépouillement systématique des Archives départementales du Jura (Lons-le-Saunier), ainsi que des archives parisiennes (Archives nationales, Bibliothèque nationale). D'autres travaux devront conduire vers les archives départementales du Doubs (Besançon), voire de la Côte-d'Or (Dijon) et du canton de Vaud (Lausanne, Suisse).

8 Ce programme de dépouillement préliminaire doit déboucher à terme sur une collaboration avec le Conseil général du Jura, le BRGM devant aboutir à une restitution cartographique des sites sur fond géologique.

Fig. 1 - Accès principal muraillé et en partie boisé

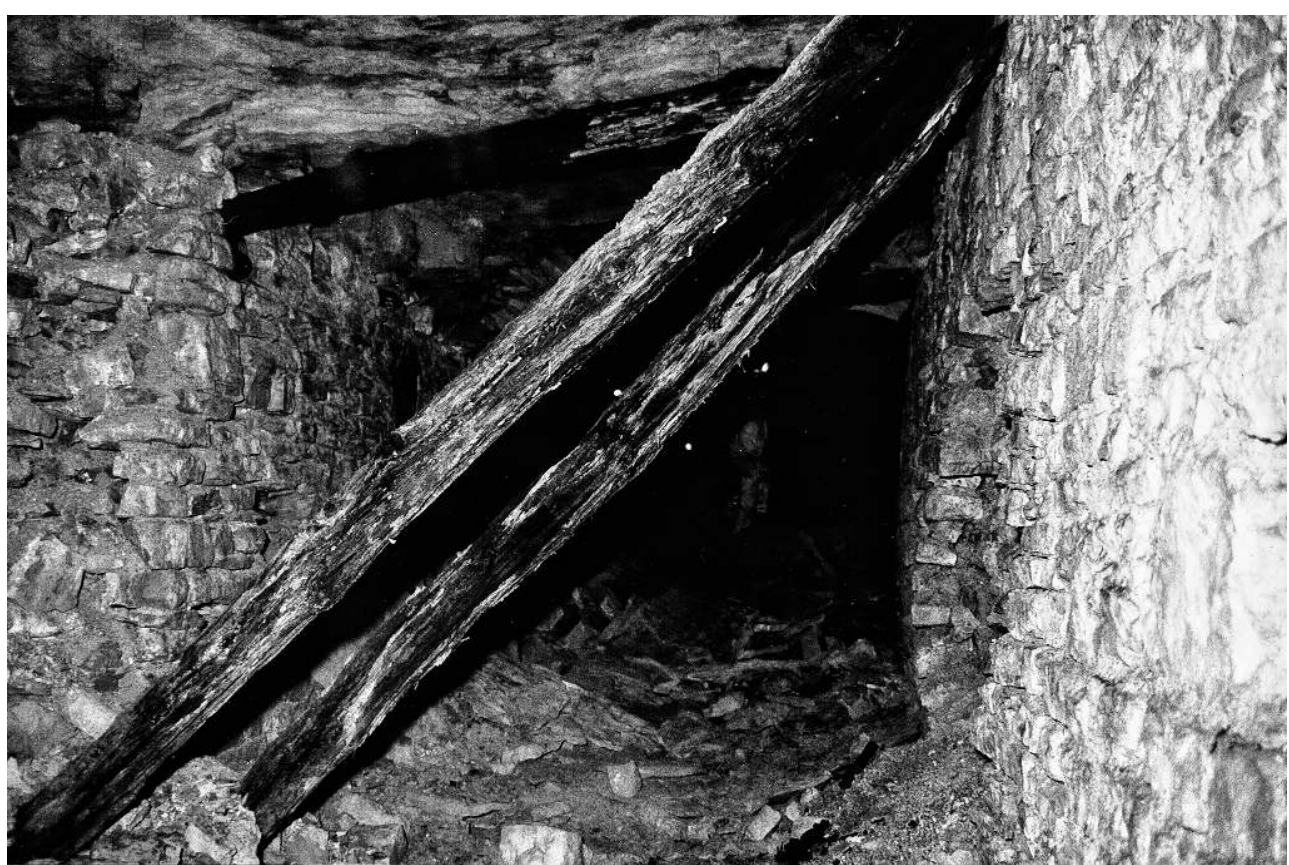

Cliché : D. Morin (CNRS). 
Fig. 2 - Voie de roulage, voie ferrée Decauville, vestige d'essieux

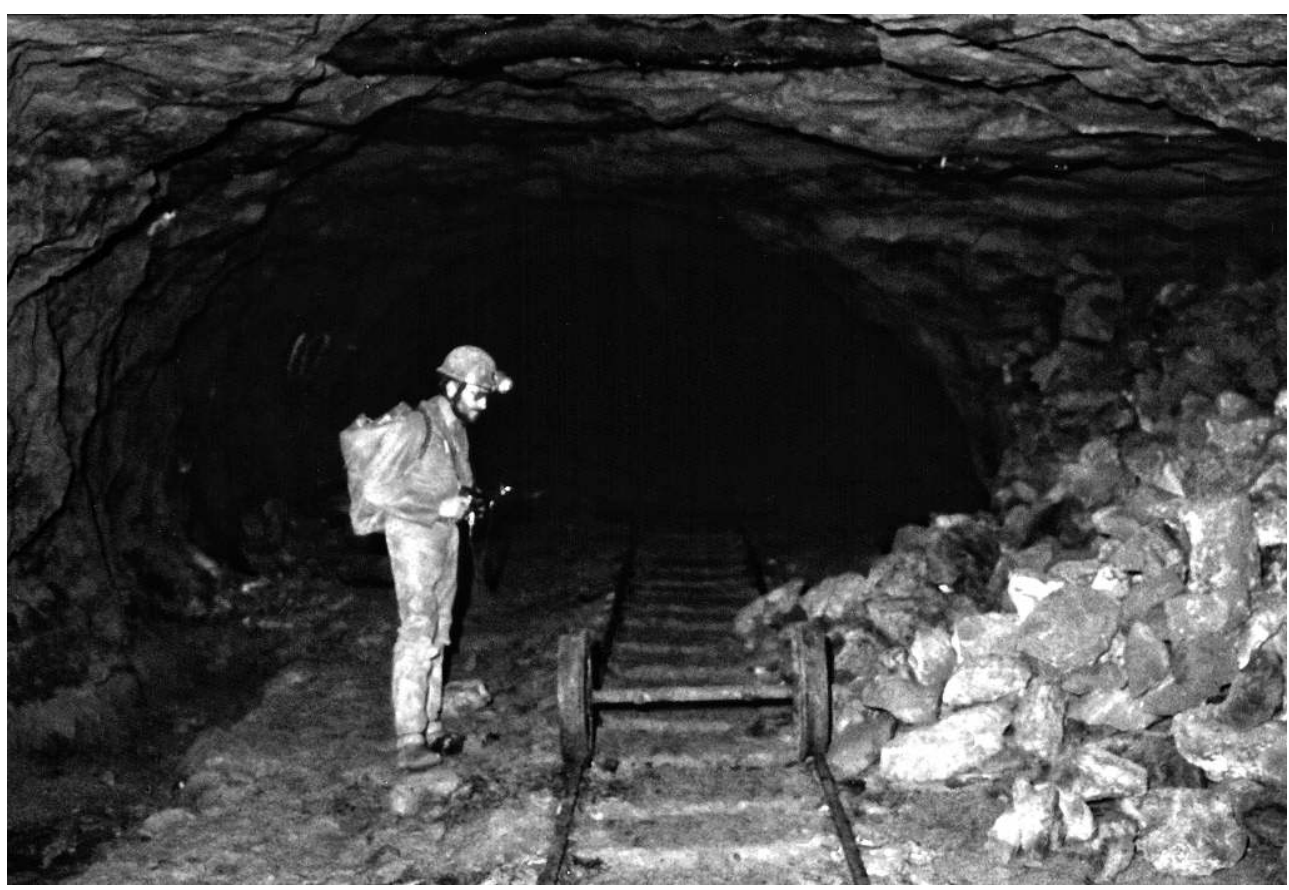

Cliché : D. Morin (CNRS) 


\section{INDEX}

\section{Année de l'opération : 2001}

lieux https://ark.frantiq.fr/ark:/26678/pcrtSEeAipsBlD, https://ark.frantiq.fr/ark:/26678/ crtWHH6M7PQ5w, https://ark.frantiq.fr/ark:/26678/pcrtX910KjTURm, https://ark.frantiq.fr/ ark:/26678/pcrtLY59dv9gsO, https://ark.frantiq.fr/ark:/26678/pcrtgQGKVmF3zR, https:// ark.frantiq.fr/ark:/26678/pcrtbQE4DrOIhi, https://ark.frantiq.fr/ark:/26678/pcrtN4sHBsvSZu chronologie https://ark.frantiq.fr/ark:/26678/pcrt59R77d1H15 nature https://ark.frantiq.fr/ark:/26678/crtPYLZpU4USm, https://ark.frantiq.fr/ark:/26678/ crtcYIBmBlBPH

sujets https://ark.frantiq.fr/ark:/26678/pcrts8SiTTY3Ka, https://ark.frantiq.fr/ark:/26678/ pcrttUONyHOUai, https://ark.frantiq.fr/ark:/26678/pcrtkn1hAXHves, https://ark.frantiq.fr/ ark:/26678/pcrtJWWucnutA0, https://ark.frantiq.fr/ark:/26678/pcrttrEq4Rcpkr, https:// ark.frantiq.fr/ark:/26678/pcrtD8bo5lH0H4, https://ark.frantiq.fr/ark:/26678/pcrtuf9JSs9vo6, https://ark.frantiq.fr/ark:/26678/pcrtA40egcJDkz, https://ark.frantiq.fr/ark:/26678/ pcrtoc8yjoUorS, https://ark.frantiq.fr/ark:/26678/pcrt5FUwwB1A6G, https://ark.frantiq.fr/ark:/ 26678/pcrtZig4pNZk7B, https://ark.frantiq.fr/ark:/26678/pcrtSVdwKcS3MI, https:// ark.frantiq.fr/ark:/26678/pcrtj3ZcwkArSR, https://ark.frantiq.fr/ark:/26678/pcrtsrWeYcRkNg, https://ark.frantiq.fr/ark:/26678/pcrt9rIFPQ997Q, https://ark.frantiq.fr/ark:/26678/ pcrtuVBFofOdjD, https://ark.frantiq.fr/ark:/26678/pcrt5bIL1UtwcT, https://ark.frantiq.fr/ark:/ 26678/pcrtgHrkHykmek, https://ark.frantiq.fr/ark:/26678/pcrtg9XR0wFYKT, https:// ark.frantiq.fr/ark:/26678/pcrtVRGDeMZs50, https://ark.frantiq.fr/ark:/26678/pcrtvskf7FZVME, https://ark.frantiq.fr/ark:/26678/pcrtf8xYVhDoIk

\section{AUTEURS}

DENIS MORIN

CNRS 